\title{
Integrated Assessment of no-Regret Climate Change Adaptation Options for Reservoir Catchment and Command Areas
}

\author{
Ajay Gajanan Bhave ${ }^{1}$ (D) Neha Mittal $^{2} \cdot$ Ashok Mishra $^{3}$. \\ Narendra Singh Raghuwanshi ${ }^{3}$
}

Received: 5 July 2015 / Accepted: 21 November 2015 /

Published online: 30 December 2015

(C) The Author(s) 2015. This article is published with open access at Springerlink.com

\begin{abstract}
The need for credible, salient and legitimate climate change adaptation options in the water sector, which target location specific adaptation requirements, is well recognized. In developing countries, the low-hanging fruit; no-regret options, should be identified with stakeholders and assessed against future changes in water availability and demand, for comparing effectiveness and robustness. Such integrated basin-scale assessments, including reservoir catchment and command areas, can suitably inform adaptation decision-making. In this study, we integrate participatory and modelling approaches for evaluation of reservoir catchment and command area no-regret options addressing water availability and demand in the Kangsabati river basin. Through multi-level stakeholder workshops we identify and prioritize options, followed by evaluation of two reservoir catchment options; check dams and increasing forest cover and three reservoir command options; changing cropping pattern, traditional ponds and waste water reuse, using the Water Evaluation And Planning (WEAP) model. We use four high resolution $(\sim 25 \mathrm{~km})$ regional climate model simulations of future
\end{abstract}

Electronic supplementary material The online version of this article (doi:10.1007/s11269-015-1207-4) contains supplementary material, which is available to authorized users.

Ajay Gajanan Bhave

ajaybhave84@gmail.com; a.g.bhave@1se.ac.uk

Neha Mittal

nehamitts@gmail.com

Ashok Mishra

amishra@agfe.iitkgp.ernet.in

Narendra Singh Raghuwanshi

nsr@agfe.iitkgp.ernet.in

1 Grantham Research Institute on Climate Change and the Environment, London School of Economics and Political Science, London WC2A 2AE, UK

2 School of Earth and Environment, University of Leeds, Leeds LS2 9JT, UK

3 Department of Agricultural and Food Engineering, Indian Institute of Technology Kharagpur, Kharagpur, West Bengal 721302, India 
climatic factors, along with non-climatic factors affecting water demand, for forcing WEAP. We find that options have varied ability in addressing adaptation requirements. Amongst catchment options, increasing forest cover addresses adaptation requirements more suitably than check dams, while in the command areas we observe mixed abilities of options, leading to the inference that combining complementary options may be a more useful strategy. We conclude by discussing our experiences with this approach in a developing country context, in terms of benefits, limitations, lessons learnt and future research directions.

Keywords Adaptation requirement - Developing country - Weap · Reservoir catchment · Reservoir command

\section{Introduction}

Successfully adapting to climate change is the major challenge humanity faces in the coming decades (Giupponi 2014; Eisenack et al. 2014). Adaptation is particularly relevant at regional and local scales where intersection of natural systems, human decision making and environmental stresses is the strongest (Wagener et al. 2010). Identifying adaptation requirements, feasible adaptation options for specific geographical contexts and evaluating their effectiveness is therefore crucial (Arnell 2010). Intensification of the hydrological cycle, changing water availability and increasing water demand, make adaptation research particularly important in developing countries (Wu et al. 2013). Recent thinking in water resources management stresses the need for understanding and modelling complex coupled human-water systems using more systems thinking because a multitude of stakeholders and factors affect water availability and demand (Loucks 2015). Integrated approaches using participatory and modelling techniques for assessing water sector adaptation options provide policy makers with hydrologically relevant information of locally suitable options which are legitimized by stakeholder involvement (Bhave et al. 2014a; Carr 2015).

Stakeholder engagement helps determine adaptation requirements and options linked to local biophysical and social vulnerabilities; critical to translating climate change impact research into effective responses (Raadgever et al. 2012; Giupponi 2014; Carr 2015). Observed and predicted changes in climatic and non-climatic factors inform the process of ascertaining adaptation requirements and are valuable inputs for the modelling process which provides credible quantitative information for comparative analyses of options. These approaches provide complementary benefits, and their harmonization in adaptation research can produce actionable and policyrelevant results. Dessai and Hulme (2004) first proposed an integrated top-down bottom-up approach for climate change impact and adaptation research, later developed by others (Füssel 2007; Wilby and Dessai 2010). Bhave et al. (2014a) developed a framework and then used a combinatory methodology involving stakeholders and water resources modelling methods for the catchment of the Kangsabati reservoir, located in West Bengal, India (Bhave et al. 2014b, 2014c).

This article attempts to increase the scope and methodological relevance of an integrated adaptation option assessment approach in two ways. Firstly stakeholder prioritized no-regret adaptation options are evaluated for the Kangsabati reservoir catchment and command areas, which form the last contributing river basin to the Ganges River Basin in India. The reservoir command area stretches beyond the naturally defined river basin, but in terms of water availability and demand is fully integrated with the reservoir catchment. Secondly we include future projections of climatic as well as non-climatic factors to better represent future changes in water availability and demand. This facilitates a comparative assessment of ability of options to satisfy specific adaptation requirements 
across catchment and command areas. This is especially relevant because while the Kangsabati reservoir catchment area is $3494 \mathrm{sq}$. $\mathrm{km}$, the command area is $5568 \mathrm{sq} . \mathrm{km}$ and more complex in terms of water requirements for agriculture, urban areas and downstream water users.

The specific research question we seek to address with this study is; how can no-regret adaptation options, identified and prioritized by stakeholders for reservoir catchment and command areas, be evaluated against specific adaptation requirements? The thematic novelty of this study is the integration of participatory and modelling techniques for holistic assessment of catchment and command areas. Moreover, since such an assessment has never been applied in a developing country context, lessons learnt and future research directions could fuel and guide future studies across river basins in the developing world. Following sections on the bottom-up and top-down approaches and discussion of evaluation results, we discuss benefits, limitations and lessons learnt, future research directions based on our research experiences.

\section{Bottom-up Approach}

Bottom-up approaches constitute stakeholder engagement for eliciting perceptions regarding existing vulnerabilities, observed climate change impacts (if any), preferred adaptation options and eliciting specific adaptation requirements. In this study, the stakeholder approach involved engaging various stakeholders, including policy makers, scientists, academicians, farmer organizations and individual farmers. Through focused group discussions, identified stakeholders interacted in a series of workshops at state, district and farmer community levels to (i) identify adaptation options and (ii) prioritize adaptation options. To identify key factors affecting vulnerability in the basin and relevant adaptation options, a 'problem web-solution web' method was developed and used, where equal representation of women farmers was sought to reduce gender bias (for methodological detail please refer to Bhave et al. 2013). Within prioritization, two methods were used; scenario analysis for determining no-regret options and Multi Criteria Analysis (MCA) for ranking adaptation options. Two MCA tools were used; pair-wise comparison and weighted summation to increase the relevance of the prioritization exercise (for methodological details please refer to Bhave et al. 2014b, 2014c).

Scenario analysis (using scenario axis approach) helps stakeholders visualize characteristics of a future scenario (van't Klooster and van Asselt 2006) for which their perceptions regarding applicability are elicited. Options applicable across all four combinations of high/low socioeconomic development and high/low climate change impact are assumed to be valuable irrespective of how future conditions evolve and are therefore termed no-regret options. MCA methods help determine criteria that are important for various locations in the study area and also rank adaptation options in terms of stakeholder preference. The prioritized criteria provide a means of evaluating the adaptation options during the modelling exercise because these criteria are understood as adaptation requirements important to stakeholders. MCA also generates ranked options based on performance against stakeholder priorities and prioritized options are assessed, using modelling techniques, against the prioritized criteria. The prioritization exercise yields seven options, of which five could be modelled using a water resources model; check dams and increasing forest cover in the reservoir catchment, and traditional ponds, changing cropping pattern and wastewater reuse in the reservoir command areas.

A critical water resources management aspect in the region is managing the temporal dimension of the rainfall-runoff process. The undulating, eroded and gullied landscape quickly converts rainfall into streamflow. Since, a large proportion of the rainfall, characterised by 
extreme rainfall events, occurs in the July to September (JJAS) monsoon months, corresponding high flows are observed during the monsoon and post monsoon $(\mathrm{ON})$ periods. Therefore the region experiences consecutive months of very high streamflow followed by consecutive dry months, with low flow conditions. State level decision makers were highly concerned about the impacts of both floods and droughts, and stressed on the need for runoff reduction and delay by facilitating ground water recharge, which farmers needed for supplemental irrigation. Sustaining dry season reservoir inflows was also considered an important adaptation requirement because it sustains irrigation in the reservoir command area. In the prioritization phase, stakeholders prioritized options, check dams and increasing forest cover, in the reservoir catchment and prioritized runoff reduction, in terms of quantity and timing of reservoir inflow, as a criterion for assessing their performance. In the reservoir command areas, excessive rice cultivation, particularly, summer (boro) rice, was considered the major driver of water consumption, leading to crop diversification as a prioritized criterion and changing cropping pattern as the corresponding option. Increasing local water availability for supplemental irrigation was elicited as an important criterion, and stakeholders prioritized traditional ponds (locally known as happa) as being particularly relevant to this criterion. Concerns regarding increasing population pressures, urbanization and potentially increasing per-capita water consumption were also raised by stakeholders and they suggested waste water reuse in towns as an important future option for addressing urban water availability issues. State level stakeholders also discussed the importance of sustaining downstream flows for domestic consumption, irrigation and maintaining flows into the Ganges, which has therefore been considered an important adaptation requirement.

\section{Top-down Approach}

\subsection{WEAP Modelling}

For analysing diverse water availability and demand options, a suitably flexible modelling framework is necessary. The Water Evaluation And Planning (WEAP) model of the Stockholm Environment Institute is a water demand, priority and preference driven model which provides a modelling framework for assessing sectoral demand, stream flow, reservoir operation, water conservation measures, allocation priorities and project cost-benefit analyses (Yates et al. 2005a; Yates et al. 2005b). It is particularly useful for comparing scenarios of hydrological change (Höllermann et al. 2010; Harma et al. 2012) and has been used for evaluating adaptation options previously (Bonelli et al. 2014; Yates et al. 2015). For this study, the Food and Agriculture Organization (FAO) rainfall-runoff method (Allen et al. 1998) available in the hydrology module of WEAP is used to simulate various hydrological processes including runoff and infiltration. In this method evapotranspiration is determined for irrigated and rainfed crops using crop coefficients $(\mathrm{Kc})$. The remainder of rainfall not consumed by evapotranspiration is simulated as runoff to a river, or distributed between surface runoff to a river and flow to groundwater. A monthly time step has been used for calibration, validation and future scenario analyses to cover the residence time of the study area, during which all flows are assumed to occur. All demand sites are located in the command areas, while WEAP catchments; nodes at which catchment processes occur, cover the entire study area as shown in Fig. 1. While the Mohanpur catchment drains runoff to the Mohanpur gauging station on the Kangsabati river, runoff from the LBMC and RBMC 


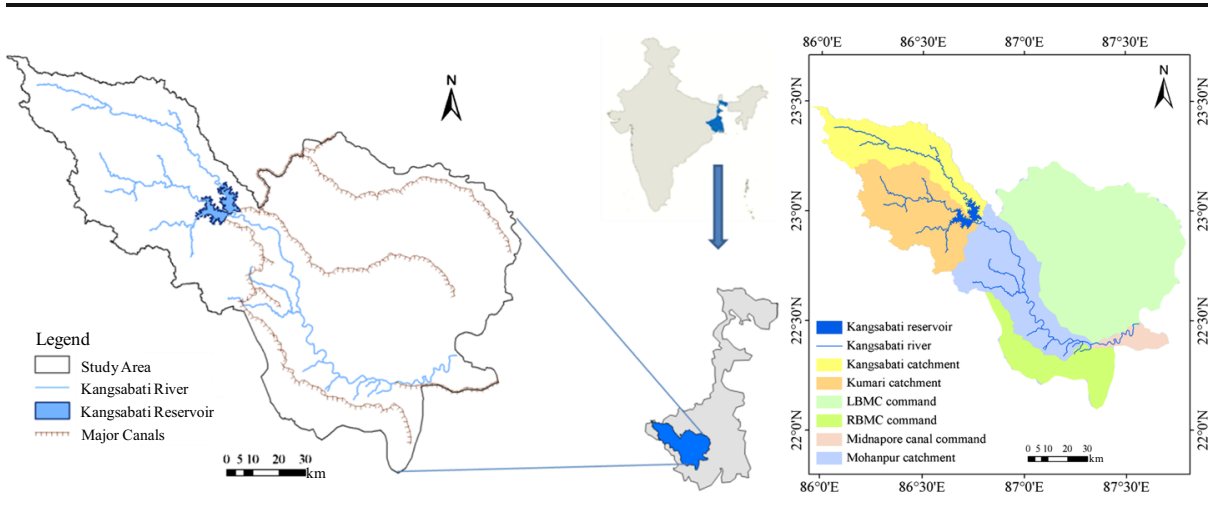

Fig. 1 Location of the Kangsabati reservoir catchment and command areas (area 9062 sq.km) (left) and WEAP catchment nodes (right)

command catchment nodes does not drain to the Kangsabati river. A small dam (anicut) at Mohanpur diverts water into the Midnapore Canal command area. The calibration and validation was carried out for the period 1991-2010, results of which have been described in detail previously (Bhave et al. 2014b, 2014c).

\subsection{Projections of Climatic and non-Climatic Factors}

Projections of climatic change, population change, urban water demand and agricultural water demand have been incorporated into this assessment. Four RCM simulations are used in this study, which represent the most comprehensive ensemble of high resolution future climate change projections available for this region (Mittal et al. 2014; Mathison et al. 2015). These simulations, based on the Special Report on Emissions Scenarios (SRES) A1B scenario were derived by forcing Regional Climate Models (RCMs) REMO and HadRM3 with two Coupled Model Intercomparison Project 3 (CMIP3) Global Climate Models (GCMs) ECHAM5 and HadCM3. This results in four RCM simulations, REMO-ECHAM5, HadRM3-ECHAM5, HadRM3-HadCM3 and REMO-HadCM3. Ability of RCM simulations to reproduce the local temperature and precipitation patterns (Fig. 2) is found to be adequate, as the comparison with Climatic Research Unit (CRU) and Asian Precipitation - Highly-Resolved Observational Data Integration Towards Evaluation of water resources (APHRODITE) data indicates. However, models reproduce spatio-temporal variation for temperature in a better manner than for precipitation, a finding consistent with previous studies in this basin and beyond (Mittal et al. 2014). Individual RCM projections along with their Multi Model Ensemble (MME) mean have been used for forcing the WEAP model, resulting in a total of five future climate simulations.

Agricultural water demand is expected to change in the future due to changing precipitation characteristics and evapotranspiration rates due to the increasing temperature. To address this irrigation requirements are modeled for the four WEAP catchment nodes in the command areas; LBMC, RBMC, Mohanpur and Midnapore Canal. For existing cropping pattern agricultural water demand is expected to increase significantly for the LBMC, RBMC and Mohanpur catchments, while Midnapore Canal Command does not indicate significant change (Supplementary S1). Three major towns exist in the command area; Jhargram, Midnapore and Kharagpur. Their water demand characteristics depend on the specified annual activity level, population and the per capita water use rate. Assumptions about these are based on a report of the Central Public Health and Environmental Engineering Organisation (2005) of the Govt. of 


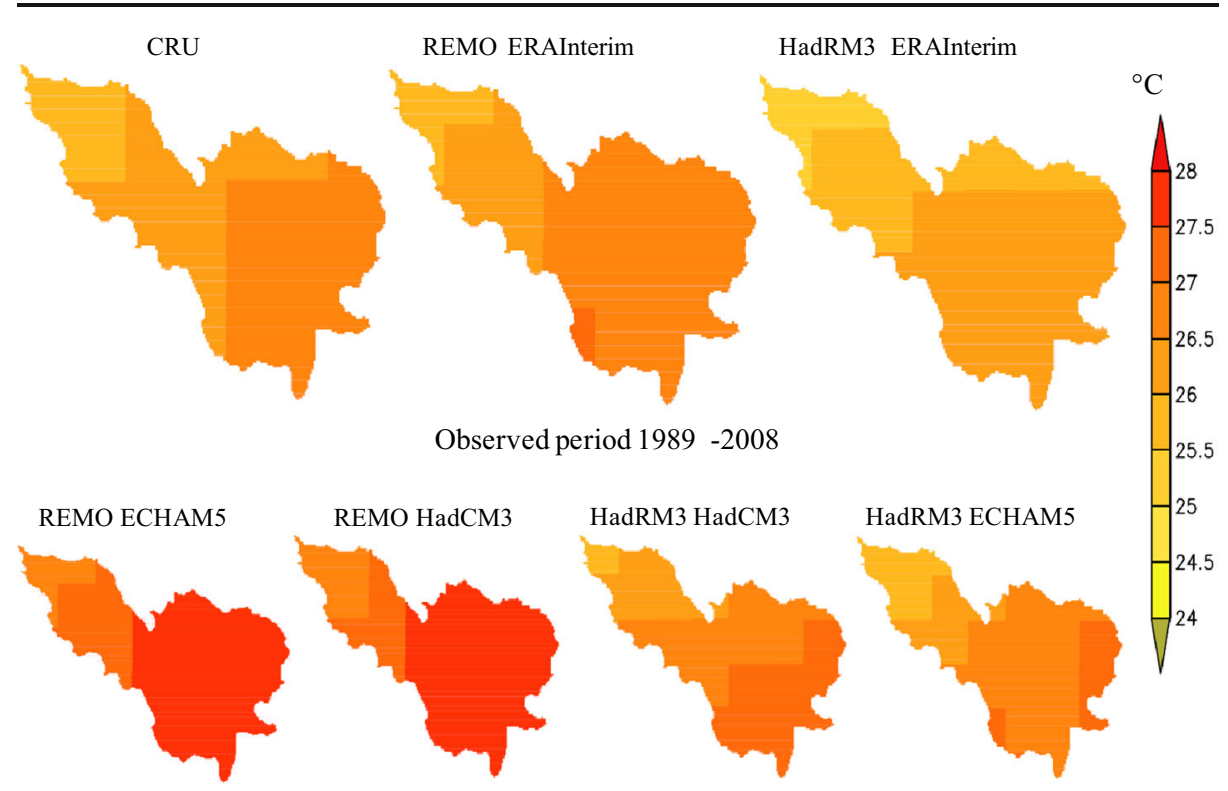

Future projections for period $2021 \quad-2050$
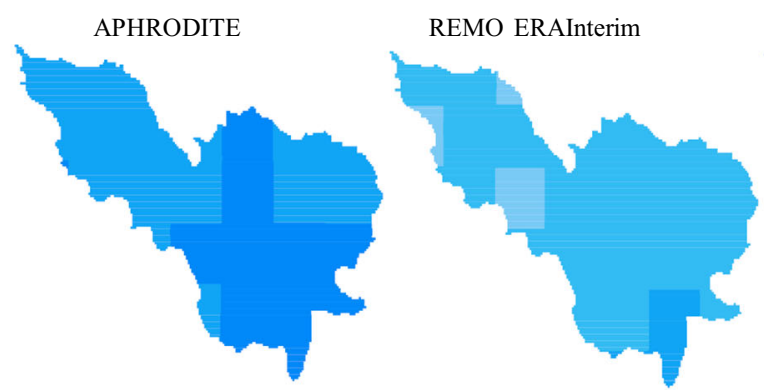

\section{HadRM3 ERAInterim}

Observed period $1989-2008$

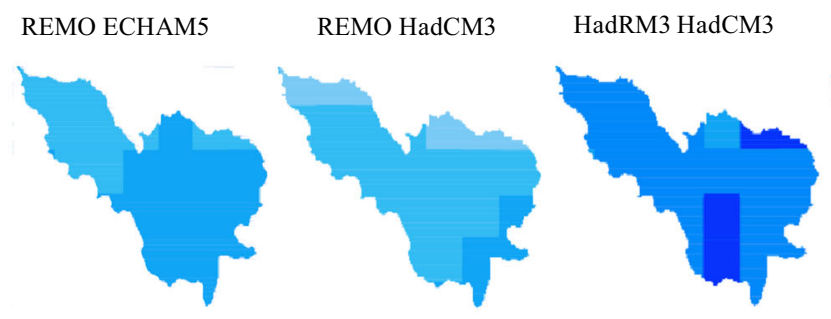

Future projections for period $2021-2050$

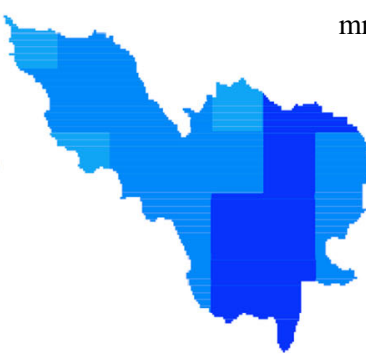

$\mathrm{mm} /$ day

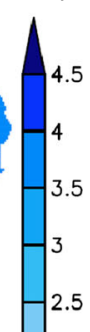

Fig. 2 Validation of REMO ERAInterim and HadRM3 ERAInterim using spatial gridded distribution of mean annual temperature and mean daily rainfall with reference to gridded CRU temperature data and gridded precipitation APHRODITE data respectively, for the period 1989-2008, and respective future projections of four RCM simulations for the period 2021-2050

India. Increasing population in these three towns in the command area (based on Mahmood and Kundu 2006) leads to increasing water demand (Supplementary S1). The use of projections of both climatic and non-climatic factors provides a more holistic understanding of 
the water availability and demand characteristics of the Business As Usual (BAU) scenario of the future.

\subsection{Future Simulations}

WEAP was run for various scenarios as described below.

Scenario 1: Baseline future scenario without adaptation (BAU)

The validated model is run for the period 2021-2050 using,

- $\quad$ Time series of climatic parameters from four RCM simulations and the MME

- Evapotranspiration rates based on Penman-Monteith method

- Land use/land cover based on the unsupervised classification of the LandSat ETM+ (Enhanced Thematic Mapper) imagery for 2011

- Same reservoir operating rules

A BAU scenario without incorporation of any adaptation options is obtained and is the reference scenario for distinguishing the effect of adaptation options.

Scenario 2: Increasing forest cover (IFC) (reservoir catchment)

IFC has been formulated according to guidelines of the National Green India Mission under the National Action Plan on Climate Change (NAPCC) (Govt. of India 2008). The mission envisages afforestation of degraded public lands and increase the canopy cover of forested areas which currently fall under the 'open forest' category ( $<40 \%$ canopy cover). Accordingly, in the WEAP model land use change is incorporated where open forest is converted to dense forest and barren land is converted to open forest (for details refer to Bhave et al. 2014b, 2014c).

Scenario 3: Check dams (CD) (reservoir catchment)

Prior to the evaluation of check dams as adaptation options, potential locations have to be determined and prioritized so as to suit local physiographical characteristics. In a Geographical Information Systems (GIS) environment using the SCS curve number method, key morphometric characteristics such as drainage network, basin geometry, drainage texture, relief and land use characteristics, nine CD locations were obtained. Check dams were applied on 2nd order streams, and assumed to have storage capacity of $0.05 \times 10^{6} \mathrm{~m}^{3}$, no buffer storage, uncontrolled spillage, surface evaporation losses, no irrigation potential and groundwater recharge (assumptions and process described in detail in Bhave et al. 2014c).

Scenario 4: Changing Cropping Pattern (CCP) (reservoir command and Midnapore Canal command areas)

The Govt. of West Bengal had proposed an optimal cropping pattern for Kharif (summer monsoon) and Rabi (winter) crops (Govt. of West Bengal 2003) (Supplementary S2) which has been developed as adaptation option CCP. Following Mehta et al. (2013) WEAP catchment nodes in the command areas were given an additional 'irrigated crop' land use. Crop 
water demand at a monthly time step was assigned using reference crop evapotranspiration and crop coefficients based on the Kangsabati Project Performance Evaluation Report (Govt. of West Bengal 2003). When sufficient water is available, the model applies water required for irrigation while taking into account conveyance and transmission losses. The cropping pattern has been distributed evenly across the command area because details regarding spatial distribution are not available. Although groundwater is used for supplemental irrigation in this region, no data is available on the extent of its use. It has been neglected in this study, since reservoir canal based irrigation is considered to be the predominant form of irrigation.

Scenario 5: Traditional ponds (TP) (reservoir command area)

Traditional ponds are usually non-masonry dug ponds having a natural drainage, used for fish cultivation, growing vegetables on its periphery and sometimes for local irrigation. Although spatially distributed on the ground, in WEAP, the storage of these tanks is aggregated for each of the four command area demand nodes. This assumption may impact evaporation rates, due to the difference in volume-area relationship. Hence, evaporation rate for ponds is assumed to be similar to that observed in the Kangsabati reservoir (Govt. of West Bengal 2003; Leemhuis et al. 2009). One pond, with $2000 \mathrm{~m}^{3}$ storage capacity is assumed for every $1 \mathrm{~km}^{2}$ area (de Condappa et al. 2009). The ponds are replenished by August (during monsoon), water is depleted by direct evaporation and groundwater recharge has been neglected. Only three WEAP catchment nodes; LBMC, RBMC and Mohanpur have been modelled with TP. This is because TP located in the Mohanpur catchment have an impact on streamflow at Mohanpur station, which affects water availability for the Midnapore Canal catchment. Therefore, to avoid a compound effect being produced in the Midnapore Canal catchment it has not been provided with TP in this study.

Scenario 6: Waste Water Reuse (WWR) (reservoir command area)

Urban WWR reduces water supply requirement by a factor of ' 1 - reuse rate'. This adaptation option is applied to three major towns in the study area; Midnapore, Kharagpur and Jhargram. Assumptions in this analysis are based on Central Public Health and Environmental Engineering Organisation (2005) and population projections are based on Mahmood and Kundu (2006). A water demand of 95 1/capita/day and population projections for the district of Paschim Midnapore (in which these three towns lie) is assumed. A gradual increase in WWR is assumed with $25 \%$ in 2021, 30\% in 2031 and $35 \%$ in 2041 to reflect the increasing focus on WWR and changing technological and infrastructural characteristics.

\section{Results and Discussion}

\subsection{BAU Scenario}

WEAP simulated monthly streamflows, forced by the five climatic model projections for the period 2021-2050, show a wide range of potential streamflow for the future. Results demonstrate a decreasing trend where annual inflows for the MME indicate a reduction of about $23 \%$ over the 30 year period, which amounts to about $0.45 \times 10^{9} \mathrm{~m}^{3}$. However, dam ability to provide irrigation water supply in command areas may not get affected significantly by the 
reduction in inflow because the reservoir storage capacity as of 2012 is about $1 / 3 \mathrm{rd}$ of the annual reservoir inflow, which is concentrated in the monsoon months (JJAS).

\subsection{Reservoir Catchment Options}

Nine suitable check dam (CD) locations were prioritized with a total catchment area of $845 \mathrm{~km}^{2}$ and they reduce streamflow compared to the BAU scenario. In the absence of irrigation from check dams in WEAP, this streamflow reduction adds to the groundwater component after evaporation losses. Greater reduction in streamflow is observed in the Kumari sub-basin (six $\mathrm{CD}$ ) than the Kangsabati sub-basin (three CD) indicating that more check dams cause greater streamflow reduction. Despite the wide range of projected monthly mean streamflow, a pattern of streamflow reduction is observed, with greater reduction during MAM compared to JJAS. Increasing Forest Cover (IFC) also reduces runoff compared to the BAU for both sub-basins, primarily during JJAS monsoon months due to increased groundwater recharge and evapotranspiration losses. The streamflow change modelled by WEAP has been found to be applicable in monsoon dominated high rainfall catchments in terms of forest cover impact on the groundwater/evapotranspiration trade-off (Krishnaswamy et al. 2013).

The percent exceedance curves for CD and IFC (Fig. 3) (positive values indicate reduction, negative values indicate increase) indicate the relative value of the two adaptation options in reducing runoff in the two sub-basins of the reservoir catchment. IFC consistently reduces streamflow for both Kangsabati and Kumari sub-basins, and is particularly effective for reducing high flows, understood as flows occurring for less than $20 \%$ of the time period. IFC also maintains or increases dry season flows reflecting its ability to address both adaptation requirements of the criterion runoff reduction. Although overall, check dams reduce streamflow, they have a dual effect because they increase high monsoon season flows, but reduce other flows. This is particularly observed in the Kangsabati sub-basin where flows which occur for $60 \%$ of the time are reduced by $\mathrm{CD}$, but the remaining high flows show a marked increase. This duality leads to two undesirable effects in terms of adaptation requirements; the magnitude of streamflow reduction is significantly lower than IFC, and the timing is contradictory to stakeholder preferred characteristics.

\subsection{Reservoir Command Area Options}

Cropping pattern affects the timing and magnitude of water demand and consequently affects hydrological characteristics. MME scenario for CCP using the optimized cropping pattern reduces water demand in Kharif and Rabi seasons for LBMC, RBMC and Mohanpur catchments which results in an increase in streamflow, particularly in monsoon months, for all five projections (Fig. 4). The cumulative excess streamflow at Mohanpur gauging station for the 30 year period based on the MME scenario is $\sim 2 \times 10^{9} \mathrm{~m}^{3}$ while a similar level of increase is observed for all RCMs. MME projections show a reduction in unmet demand compared to the BAU scenario particularly in the Kharif season. However, although the magnitude of reduction in unmet demand for the Rabi season is lower than Kharif season, proportion of unmet demand compared to the BAU scenario is similar. The uncertainty band is quite wide for all catchments, but the MME indicates a consistent reduction in water demand. $\mathrm{CCP}$ also reduces water demand in Mohanpur catchment which increases streamflow at the Mohanpur gauging station. This increase also helps reduce unmet demand in the Midnapore canal command area. 

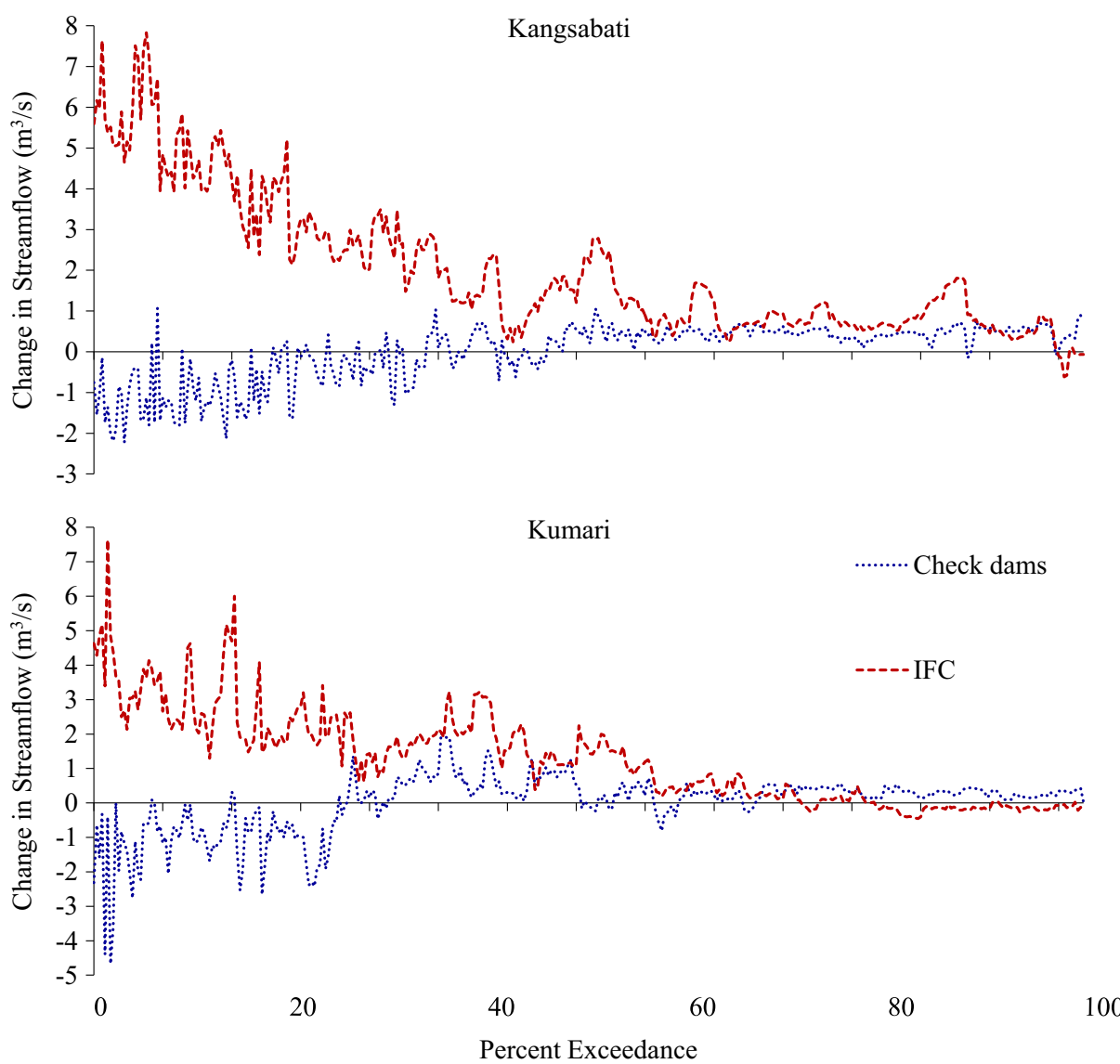

Fig. 3 Change in percent exceedance of streamflow for adaptation options CD and IFC compared to BAU scenario, estimated using MME projections for the 2021-2050 period for the Kangsabati sub-basin

Traditional ponds reduces water demand for all three catchments with the cumulative change till 2050 being largest for LBMC, of up to $\sim 4.5 \times 10^{9} \mathrm{~m}^{3}$ with unmet demand predominantly during the Kharif season (Supplementary S3). Percent exceedance curves (Fig. 5) demonstrate an overlap in the uncertainty bands of BAU and CCP and BAU and TP. However, the difference between the areas under the curve for MME BAU and MME CCP and for MME BAU and MME TP show the scale of reduction of unmet demand. The peak unmet demand reduces from $\sim 0.78 \times 10^{9} \mathrm{~m}^{3}$ to about $\sim 0.42 \times 10^{9} \mathrm{~m}^{3}$ for the MME CCP while for MME TP it reduces from $\sim 0.78 \times 10^{9} \mathrm{~m}^{3}$ to $\sim 0.70 \times 10^{9} \mathrm{~m}^{3}$. This significant reduction caused by CCP compared to TP indicates the value of this option. Contrary to TP, CCP does not increase local water availability but by reducing water demand makes better use of water available for irrigation. However, it is important to note that Midnapore Canal catchment, which has not been provided with traditional ponds in the WEAP model is benefited only through the improved timing of water availability in the Kangsabati river for satisfying irrigation water demand. Therefore application of TP in Midnapore canal command may further reduce the peak unmet demand. 

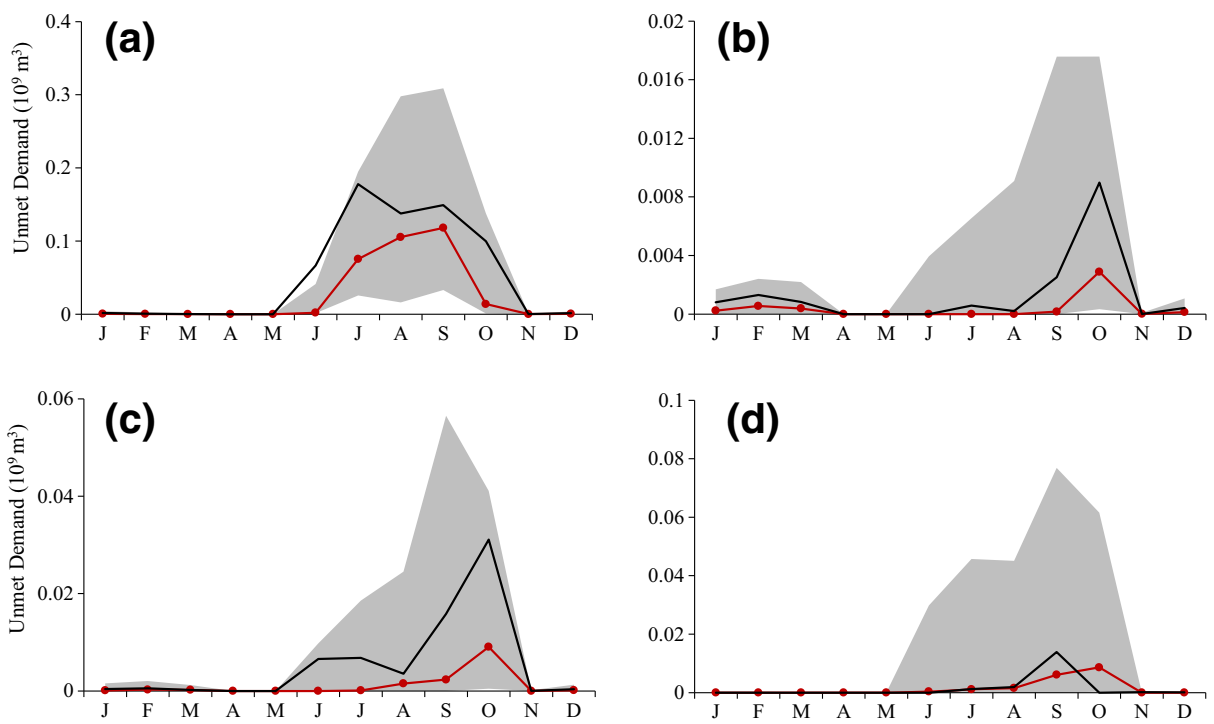

Fig. 4 Mean monthly unmet demand for the four irrigated catchment nodes, a) LBMC, b) RBMC, c) Mohanpur and d) Midnapore Canal for the future time period (2021-2050). Projections for MME of BAU and MME of CCP are shown along with the uncertainty band (shaded) which represents the range of projections for four RCM simulations.

The four catchments have varying degrees (\%) of coverage of water supply requirement as this is a function of the irrigated area, source of water and its size and the priority given to that particular catchment for water supply (Fig. 6). LBMC, RBMC and Mohanpur catchments, which have TP, show significantly larger change in coverage than Midnapore Canal command. Duration of $100 \%$ coverage of water demand increases from $\sim 68 \%$ to $\sim 70 \%$ for LBMC, from $\sim 75 \%$ to $\sim 80 \%$ for RBMC and from $\sim 72 \%$ to $\sim 77 \%$ for Mohanpur. Most importantly, TP proves to be robust option since for LBMC, RBMC and Mohanpur catchments, the demand site coverage does not become zero for any duration for the MME and most RCM simulations. TP also changes streamflow where high flows at Mohanpur station are
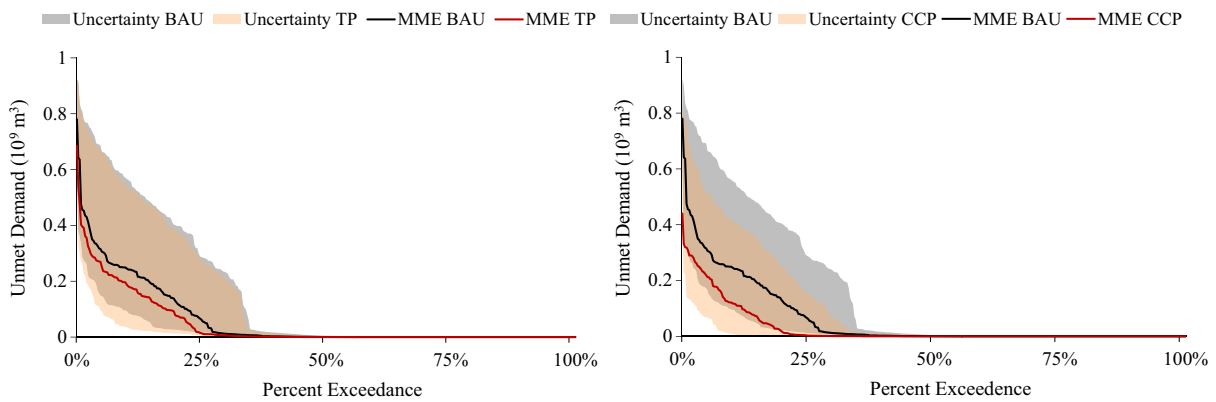

Fig. 5 Percent exceedance plot for the combined unmet demand of the four WEAP catchment nodes, LBMC, RBMC, Mohanpur and Midnapore Canal for CCP and TP adaptation options with their respective uncertainty bands (shaded) which represents the range of projections for four RCM simulations 

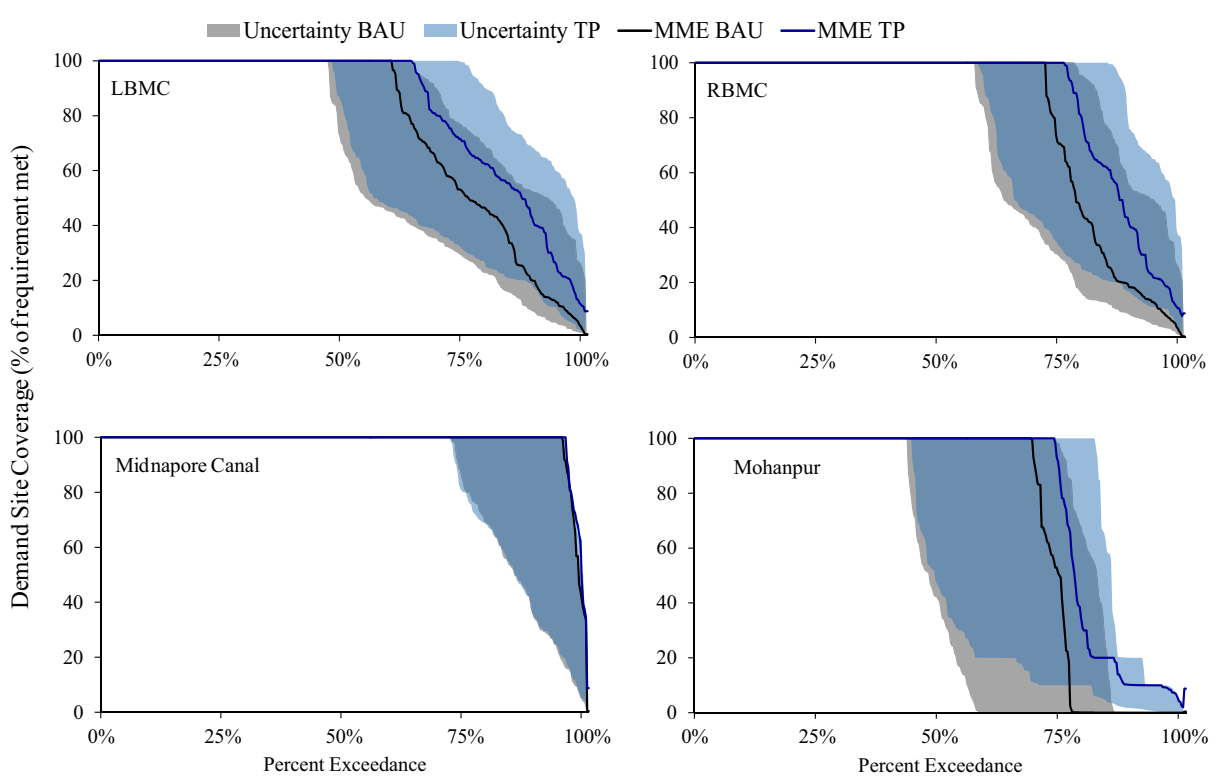

Fig. 6 Percent exceedance plots for the demand site coverage of the four WEAP catchment nodes, LBMC, RBMC, Mohanpur and Midnapore Canal for MME projections of BAU and TP and their respective uncertainty bands

reduced by up to about $50 \times 10^{6} \mathrm{~m}^{3}$ while low flows are maintained. This indicates that traditional ponds located in Mohanpur catchment act as a buffer for high rainfall events and therefore reduce the intensity of floods at Mohanpur gauging station. TP also maintain or marginally increase the low flows and therefore are useful for maintaining water availability for downstream users.

WWR as an adaptation option was applied to the cities Jhargram, Midnapore and Kharagpur which caused changes in the water demand characteristics of the cities. These changes caused alterations in the streamflow downstream of the cities at the Mohanpur gauging station as indicated by the percent exceedance curve (Fig. 7). The figure indicates a greater increase in high flows (0-25\%) compared to the low flows (75-100\%). Increase in existing high flows, which occur during monsoon season may increase the risk of flooding in the downstream sections. On the other hand, an increase of up to $0.5 \times 10^{6} \mathrm{~m}^{3}$ during the dry months will help improve water availability in the downstream sections.

Unmet demand related to urban water supply in the three towns also reduces with a progressive reduction in the future (Supplementary S4). The monthly distribution (inset diagram S4) indicates most change to be during the JJAS months. The reduction in unmet demand for Jhargram is the lowest because it lies in the upstream of Midnapore and Kharagpur and therefore has less unmet demand during BAU. Although the monthly unmet demand reductions indicate that the largest reduction is seen for Kharagpur, the trend for Midnapore is stronger. This is because demand in Kharagpur, which is downstream of the Jhargram and Midnapore, is met only after the demands of Jhargram and Midnapore have been met but a larger population means greater effect. A crucial result is that unmet demand for the cities does not become zero despite increasing the reuse rate from $25 \%$ to $35 \%$, indicating the scale of urban water resources adaptation challenge in developing country contexts. 


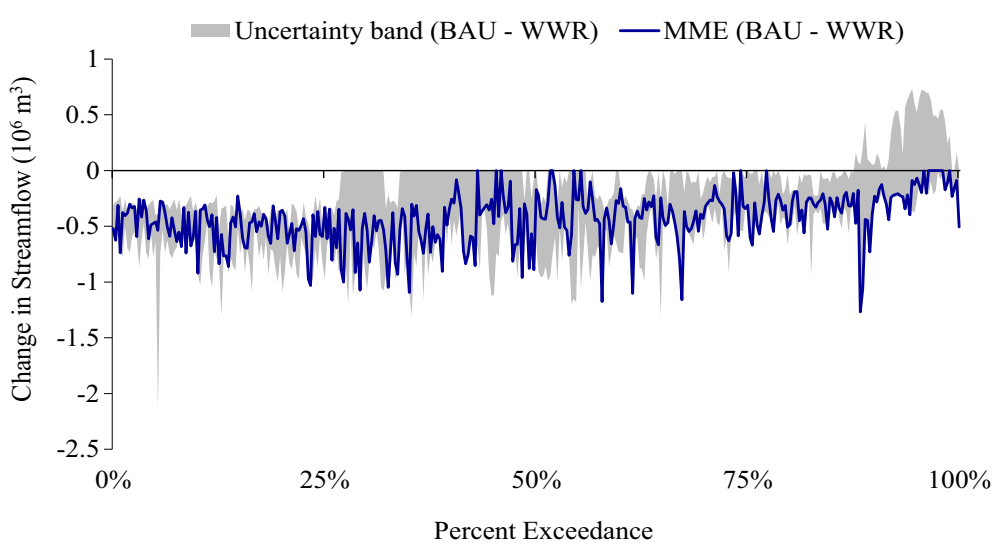

Fig. 7 Projected change in monthly streamflow at Mohanpur gauge station for the MME and for the uncertainty band

\subsection{Uncertainty in the Effect of Adaptation Options}

Changes in water availability and demand effected by adaptation options affect runoff volume and consequently, monthly streamflow pattern (Fig. 8). Uncertainty band for $\mathrm{CD}$ indicates a consistent sign of change in streamflow where a reduction is expected for all months. There is greater agreement between models regarding magnitude of change for the post monsoon (ON) and winter (DJF) months compared to the summer months (MAM) where the uncertainty is largest for May. Uncertainty range for magnitude of streamflow change for IFC is larger for all months compared to CD but the sign of streamflow change is certain. A difference of 2-3 orders of magnitude observed between the effects produced by CD and IFC suitably demonstrates the value of IFC as an adaptation strategy over CD. In the reservoir command area, CCP increases streamflow in proportion to the reduced water demand brought about by the shift from monoculture cultivation of water intensive rice to crops such as maize and oilseeds. For most months, the uncertainty band reflects the pattern of streamflow changes as shown by the MME, except for June when there is uncertainty regarding the sign of change of streamflow.

Unlike CCP, TP reduces streamflow at Mohanpur compared to the BAU scenario predominantly for the pre-monsoon months of April and May and during the monsoon months June, July and August. Although the sign of change is consistent, with a reduction during all months for all models, as indicated by the uncertainty band, the projected magnitude of change is uncertain. On the other hand, WWR is expected to consistently increase streamflow at Mohanpur upto $\sim 0.9 \times 10^{6} \mathrm{~m}^{3}$ for the MME projections. This is because, while the relationship between water demand and availability is more dynamic for the CCP and TP, a well-defined and consistent quantum of water is reused in the towns. Analysis shows that CCP increases streamflow by $\sim 50$ times more than WWR at Mohanpur, which is an important adaptation requirement. However the timing of this increase being during the monsoon (JJAS) season will increase the risk of flooding. On the other hand, WWR increases streamflow during all months with maximum increase occurring during the summer months (MAM). Therefore while uncertainty assessment and evaluation of the ability to satisfy adaptation requirements reveals the usefulness of both CCP and WWR, it is important to note that they address different adaptation requirements of the study area. 

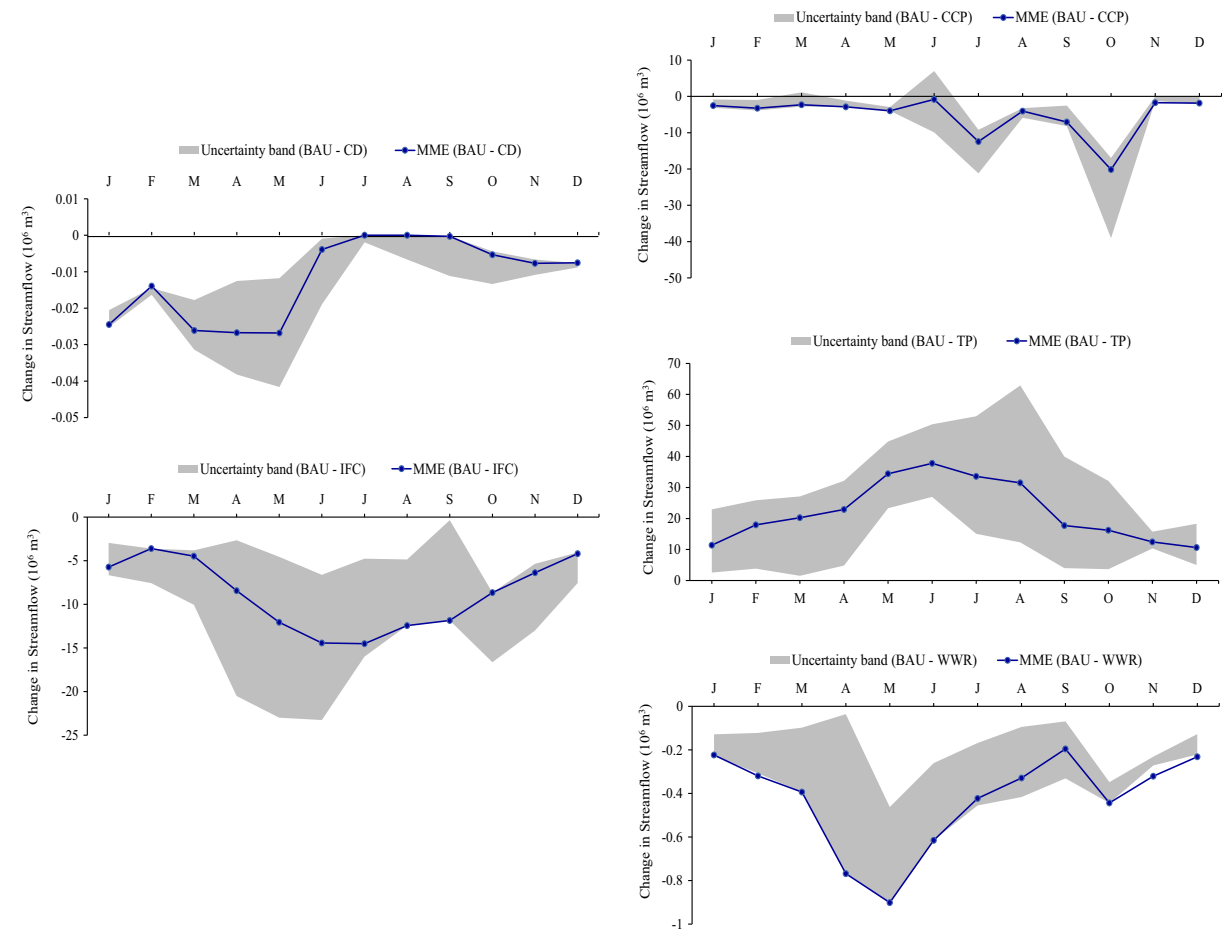

Fig. 8 Change in monthly Kangsabati reservoir inflow for adaptation options in the reservoir catchment CD and IFC (left) compared to the BAU. Uncertainty band (shaded) represents the range of projections for four RCM simulations while positive values indicate reduction and negative values indicate streamflow increase. Similarly, streamflow projections for three reservoir command area options; CCP, TP and WWR (right) at Mohanpur gauging station for the future period (2021-2050)

\section{Lessons and Conclusions}

\section{5. 1. Benefits of an Integrated Approach}

- The research approach increases credibility, salience and legitimacy because there are two levels of integration; integrating methods from social sciences and natural sciences and, integrating catchment hydrology and water demand characteristics. The approach leveraged strengths of individual disciplines increasing salience and legitimacy. Expanding modelling boundaries beyond the river basin to include the reservoir command area improved representation of water resources characteristics; increasing scientific credibility. In developing countries greater interdisciplinary exchange is needed to involve all knowledge bearers while analysing both catchment and command areas may increase holistic understanding and reduce conflict.

- Interaction with decision makers, scientists and farmers improved researchers' understanding of ground realities and characteristics that would otherwise not be included. The interaction also benefited the stakeholders through increased awareness of how climate change could increase vulnerability, and the necessity of planned adaptation. Such 
processes may also foster better knowledge exchange amongst stakeholders, thus improving relations.

- Adaptation needs to target specific vulnerabilities which may depend on climate change impacts at other locations. For example, change in reservoir catchment rainfall affects water availability for command area agriculture. Integrated assessment improves understanding, modelling and analysis of such tele-connected impacts and implications for adaptation.

- Adaptation in water resources will have to address both water availability (quantity and timing) and water demand. The approach generates better understanding of relative ability of options to address adaptation requirements, possible linkages and extent to which adaptation is necessary.

\subsection{2 Limitations and Problems with Integrated Approach}

- Modelling reservoir and command areas requires details about demand management, canal releases, supply priorities, types of crops grown etc.; information not always available in developing countries.

- Resource-intensiveness of the approach presents a challenge for large scale replication of such studies in developing countries, since, time, money and human resources are necessary for data collection, stakeholder consultations and modelling analyses.

- WEAP model, like any model has advantages and limitations which need to considered prior to the analysis. For example, here, a monthly time step has been used, which may not be appropriate for all studies or for a particular adaptation option.

- All prioritized options could not be modelled using a water resources model (for example, agricultural education) and this presents a fundamental limitation in terms of evaluation of adaptation options. More systemic understanding and corresponding modelling efforts are needed for evaluating the potential of such options.

- This study, benefits from the higher spatial resolution of $\sim 25 \mathrm{~km}$, but is based on CMIP3 models compared to the more recent CMIP5 GCMs, which are based on Representative Concentration Pathways (RCPs). However, since CMIP5 models demonstrate similar ability to reproduce the Indian monsoon (Turner and Annamalai 2012) as CMIP3 models, we consider this study to be relevant. However, we do realize that more model simulations, preferably at a higher resolution, enhances the range of possible climatic futures and can therefore ably assist in robust adaptation decision making.

- Stakeholder engagement may be challenging because diverse groups, with conflicting demands and inadequate cross-communication, have to be managed in a way so that research objectives are fulfilled. Stakeholders have different expectations from the workshops and for better engagement have to be explained about its purpose, method, and, critically, value of such research for them.

- The study approach integrates stakeholder priorities into the modelling process but does not fully address the complex coupled human-water interaction, which is an important research direction in the Anthropocene (Wagener et al. 2010). Greater quantitative understanding of interactions and feedbacks, currently missing in developing countries, will need to be incorporated into models for better water resource simulations. 


\subsection{3 Lessons Learnt}

- Customization of methods is necessary to suit physiographical context, stakeholder characteristics and local sensitivities but reduces reproducibility and comparability, particularly of the participatory process. Different individuals, socio-economic conditions, socio-ecological contexts and engagement of local partners determines the extent to which customization may be necessary. A useful, albeit resource intensive, way could be to use a common modelling framework across case studies to increase comparability and scientific credibility. Considering that this study is centred on a reservoir, using analogous physical settings could increase comparability, while customizing the participatory approach would lend salience and legitimacy.

- Analysis of adaptation measures will not address key challenges without consultations with relevant local stakeholders and policy makers. Their engagement requires buy-in, for which trust has to be cultivated. Identifying champions in relevant organizations could lead to buy-in and may be critical for ensuring long-term interest and engagement. Moreover, in our experience, an important requirement of successful stakeholder engagement is ensuring that stakeholders have useful takeaways such as new information and insights, especially if too many similar projects have caused stakeholder fatigue.

- We notice an inherent contradiction between what stakeholders suggest as important and actual behaviour. While crop diversification was a prioritized criterion, currently $\sim 89 \%$ of all crop production in this region is rice, a water intensive crop. Cultural preferences, market demand and prices, and perhaps ease of storage and transport influence the choice of crop. Therefore greater integration of policies will be necessary to influence stakeholder behaviour for ensuring successful adaptation.

- Adaptation options cannot always be implemented in isolation because different options address adaptation requirements differently. It is therefore important to evaluate the effect of a suite of overlapping adaptation options in an integrated manner. Cumulative effects across a range of criteria and adaptation requirements could help decision makers prepare portfolios of options and determine relative scales of implementation. Such research-led decision making will be critical for the success of planned adaptation response, particularly in developing countries, because rapidly changing socio-economic, infrastructural and environmental conditions necessitate critical analysis of projected changes for a multitude of factors.

\subsection{4 Opportunities for Further Research}

- Addressing issues related to cross-sectoral vulnerability and resilience and interdependence of sectors is very important (eg. energy, water, road infrastructure, telecommunications etc.). Therefore meaningful analyses can include multiple interlinked aspects and also address interdisciplinary research domains like the Water-Energy-Food nexus and linkages with climate change adaptation.

- This study considered urban population projections but not scenarios of rapid urbanization through rural to urban migration. However, expanding urban centres in developing countries will necessitate application of an array of disparate adaptation measures across urban, peri-urban and rural areas and will need to account for rapid urbanization. Increasingly, river basin scale studies in developing countries will need to incorporate 
this mosaic of human habitation which has very different characteristics and influence on the water system.

- Research methods need to be developed for understanding the proportion of impacts that can be managed by implementing adaptation options, associated costs, residual impacts and biophysical and socio-economic limits to planned adaptation, so as to provide policy relevant information to decision makers.

Acknowledgments We wish to acknowledge the financial support from the HighNoon project, funded by the European Commission Framework Programme 7, under Grant Number 227087. Future climate simulations used in this study are available through the HighNoon website (http://www.eu-highnoon.org/)

Open Access This article is distributed under the terms of the Creative Commons Attribution 4.0 International License (http://creativecommons.org/licenses/by/4.0/), which permits unrestricted use, distribution, and reproduction in any medium, provided you give appropriate credit to the original author(s) and the source, provide a link to the Creative Commons license, and indicate if changes were made.

\section{References}

Allen R G, Pereira L S, Raes D, Smith M (1998). Crop evapotranspiration-Guidelines for computing crop water requirements-FAO Irrigation and Drainage Paper 56. FAO, Rome. 300, 6541

Arnell N (2010) Adapting to climate change: an evolving research programme. Clim Chang 100(1):107-111. doi: $10.1007 /$ s10584-010-9839-0

Bhave AG, Mishra A, Groot A (2013) Sub-basin scale characterization of climate change vulnerability, impacts and adaptation in an Indian river basin. Reg Environ Chang 13(5):1087-1098. doi:10.1007/s10113-0130416-8

Bhave AG, Mishra A, Raghuwanshi NS (2014a) A brief review of assessment approaches that support evaluation of climate change adaptation options in the water sector. Wat Pol 16(5):959-972. doi: 10.2166/wp.2014.097

Bhave AG, Mishra A, Raghuwanshi NS (2014b) A combined bottom-up and top-down approach for assessment of climate change adaptation options. J. of Hydrol. 518:150-161. doi:10.1016/j.jhydrol.2013.08.039

Bhave AG, Mishra A, Raghuwanshi NS (2014c) Evaluation of hydrological effect of stakeholder prioritized climate change adaptation options based on multi-model regional climate projections. Clim Chang 123:225239. doi:10.1007/s10584-014-1061-Z

Bonelli S, Vicuña S, Meza FJ, Gironas J, Barton J (2014) Incorporating climate change adaptation strategies in urban water supply planning: the case of central Chile. J of Wat and Clim Chang 5(3):357-376. doi:10.2166/ wcc. 2014.037

Carr G (2015) Stakeholder and public participation in river basin management-an introduction. Wiley interdisci. Rev. Wat 2(4):393-405. doi:10.1002/wat2.1086

Central Public Health and Environmental Engineering Organisation (2005) Status of water supply, sanitation and solid waste management in urban areas, Research Study Series No. 88, Ministry of Urban Development, Government of India

de Condappa D, Chaponnière A, Lemoalle J (2009) A decision-support tool for water allocation in the Volta basin. Water Int 34(1):71-87. doi:10.1080/02508060802677861

Dessai S, Hulme M (2004) Does climate adaptation policy need Probabilities? Clim Pol 4:107-128. doi:10.1080/ 14693062.2004.9685515

Eisenack K, Moser SC, Hoffmann E, Klein RJ, Oberlack C, Pechan A, Rotter M, Termeer CJ (2014) Explaining and overcoming barriers to climate change adaptation. Nat Clim Chang 4(10):867-872. doi:10.1038/ nclimate 2350

Füssel HM (2007) Adaptation planning for climate change: concepts assessment approaches and key lessons, sustain. Sci 2:265-275. doi:10.1007/s11625-007-0032-y

Giupponi C (2014) Decision support for mainstreaming climate change adaptation in water resources management. Wat. Resour. Manag. 28(13):4795-4808

Govt. of India (2008). National Action Plan on Climate Change. URL: http://pmindia.gov.in/climate_change_ english.pdf 
Govt. of West Bengal (2003). Performance evaluation study and system analysis of kangsabati reservoir project. Vols. I and II, Kolkata, West Bengal

Harma KJ, Johnson MS, Cohen SJ (2012) Future water supply and demand in the Okanagan basin, British Columbia: a scenario-based analysis of multiple, interacting stressors. Wat. Resour. Manag. 26(3):667-689. doi:10.1007/s11269-011-9938-3

Höllermann B, Giertz S, Diekkrüger B (2010) Benin 2025-balancing future water availability and demand using the WEAP 'water evaluation and planning'system. Wat. Resour. Manag. 24(13):3591-3613

Krishnaswamy J, Bonell M, Venkatesh B, Purandara BK, Rakesh KN, Lele S, Kiran MC, Reddy V, Badiger S (2013) The groundwater recharge response and hydrologic services of tropical humid forest ecosystems to use and reforestation: support for the "infiltration-evapotranspiration trade-off hypothesis". J of Hydrol 498: 191-209. doi:10.1016/j.jhydrol.2013.06.034

Leemhuis C, Jung G, Kasei R, Liebe J (2009) The Volta basin water allocation system: assessing the impact of small-scale reservoir development on the water resources of the Volta basin. West Africa Adv in Geosci 21(21):57-62. doi:10.5194/adgeo-21-57-2009

Loucks DP (2015) Debates - perspectives on sociohydrology: simulating hydrologic-human interactions. Wat Resour Res. doi:10.1002/2015WR017002

Mahmood A, Kundu A (2006) Demographic projections for India 2006-2051. Jawaharlal Nehru University, New Delhi, Regional variations

Mathison C, Wiltshire AJ, Falloon P, Challinor AJ (2015) South Asia river flow projections and their implications for water resources. Hydrol Earth Syst Sci Discuss 12:5789-5840. doi:10.5194/hessd-12-5789-2015

Mehta VK, Haden VR, Joyce BA, Purkey DR, Jackson LE (2013) Irrigation demand and supply, given projections of climate and land-use change, in Yolo county. California Agri Water Manag 117:70-82. doi: 10.1016/j.agwat.2012.10.021

Mittal N, Mishra A, Singh R, Kumar P (2014) Assessing future changes in seasonal climatic extremes in the Ganges river basin using an ensemble of regional climate models. Clim Chang 123(2):273-286. doi:10. 1007/s10584-014-1056-9

Raadgever GT, Mostert E, Van de Giesen NC (2012) Learning from collaborative research in water management practice. Wat Resour Manag 26(11):3251-3266

Turner AG, Annamalai H (2012) Climate change and the south Asian summer monsoon. Nat Clim Chang 2(8): 587-595. doi:10.1038/nclimate1495

van’t Klooster SA, van Asselt MB (2006) Practising the scenario-axes technique. Futures 38(1):15-30. doi:10. 1016/j.futures.2005.04.019

Wagener T, Sivapalan M, Troch PA, McGlynn BL, Harman CJ, Gupta HV, Kumar P, Rao SC, Basu NB, Wilson JS (2010) The future of hydrology: an evolving science for a changing world. Wat. Resour. Res. 46(5). doi: 10.1029/2009WR008906

Wilby RL, Dessai S (2010) Robust adaptation to climate change. Weather 65:180-185. doi:10.1002/wea.543

Wu P, Christidis N, Stott P (2013) Anthropogenic impact on earth/'s hydrological cycle. Nat Clim Chang 3(9): 807-810. doi:10.1038/nclimate1932

Yates D, Sieber J, Purkey D, Huber-Lee A (2005a) WEAP21 - a demand, priority, and preference-driven water planning model: part 1: model characteristics. Water Int 30(4):487-500. doi:10.1080/02508060508691893

Yates D, Sieber J, Purkey D, Huber-Lee A, Galbraith H (2005b) WEAP21: a demand, priority, and preference driven water planning model: part 2, aiding freshwater ecosystem service evaluation. Water Int 30:487-500. doi:10.1080/02508060508691894

Yates D, Miller KA, Wilby RL, Kaatz L (2015) Decision-centric adaptation appraisal for water management across Colorado's continental divide. Clim Risk Manag. doi:10.1016/j.crm.2015.06.001 